\title{
STEM CHALLENGE Use of Matrices in Graphic Designing
}

Salman Ahmad ${ }^{1}$

${ }^{1}$ Affiliation not available

May 5, 2021

Use of Matrices in Graphic Designing

Time required: 60 minutes

\section{Challenge:}

As you are introduced to Matrices. Now you have to practice it through STEM challenge by designing graphics manually with the help of matrices.

Resource kit:

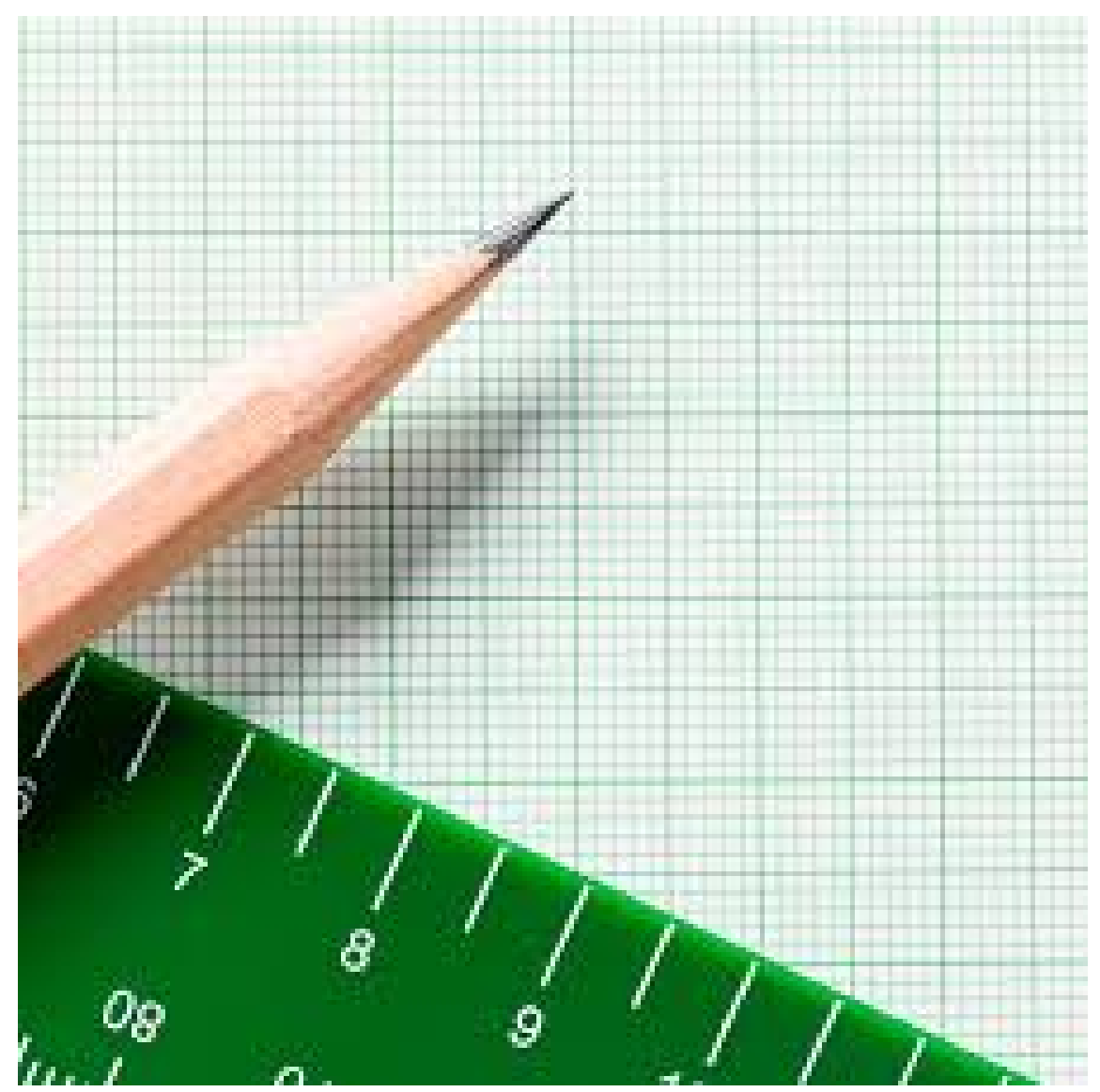



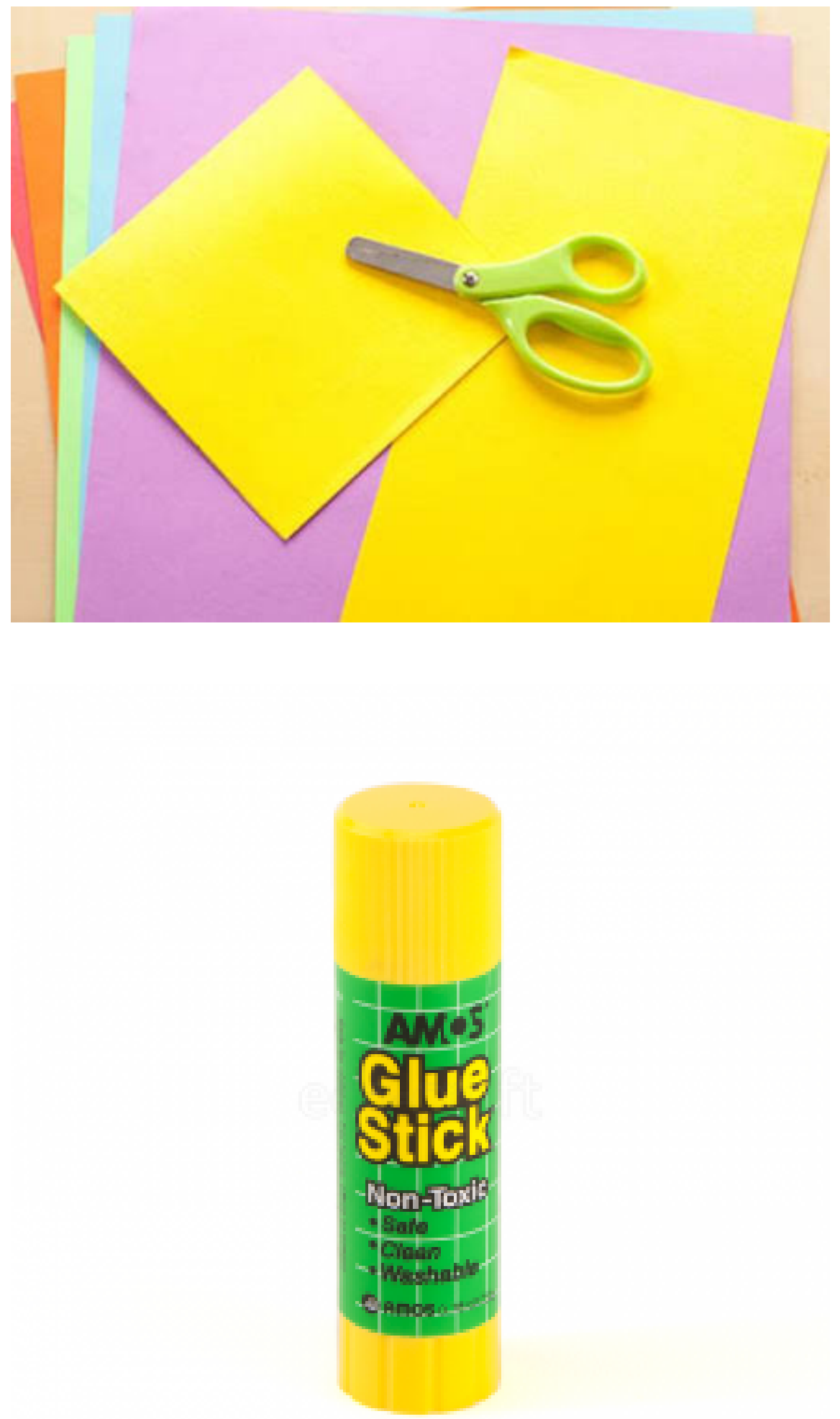


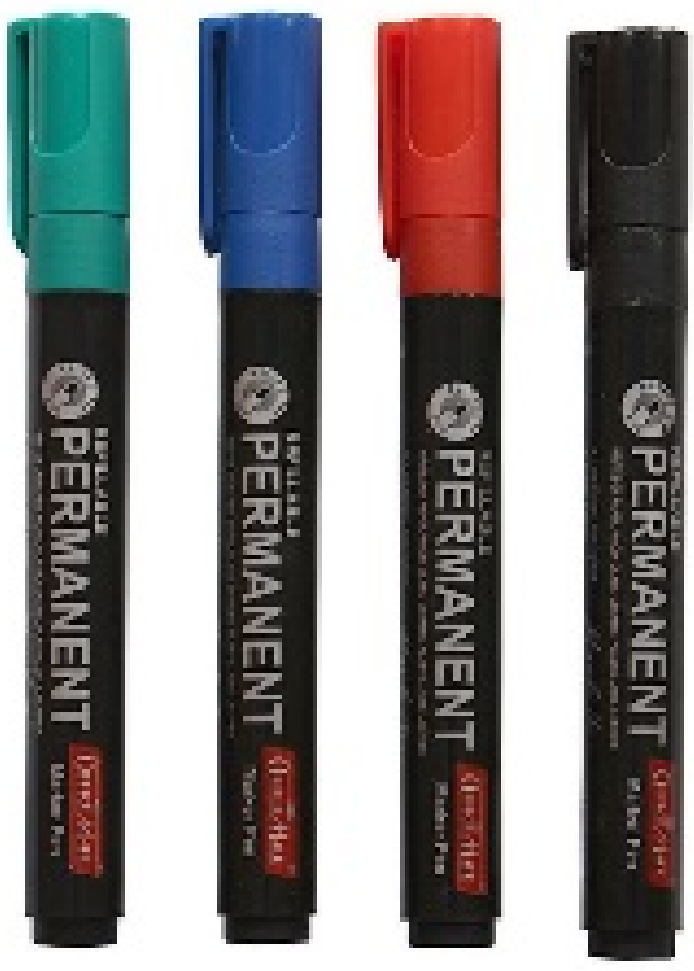




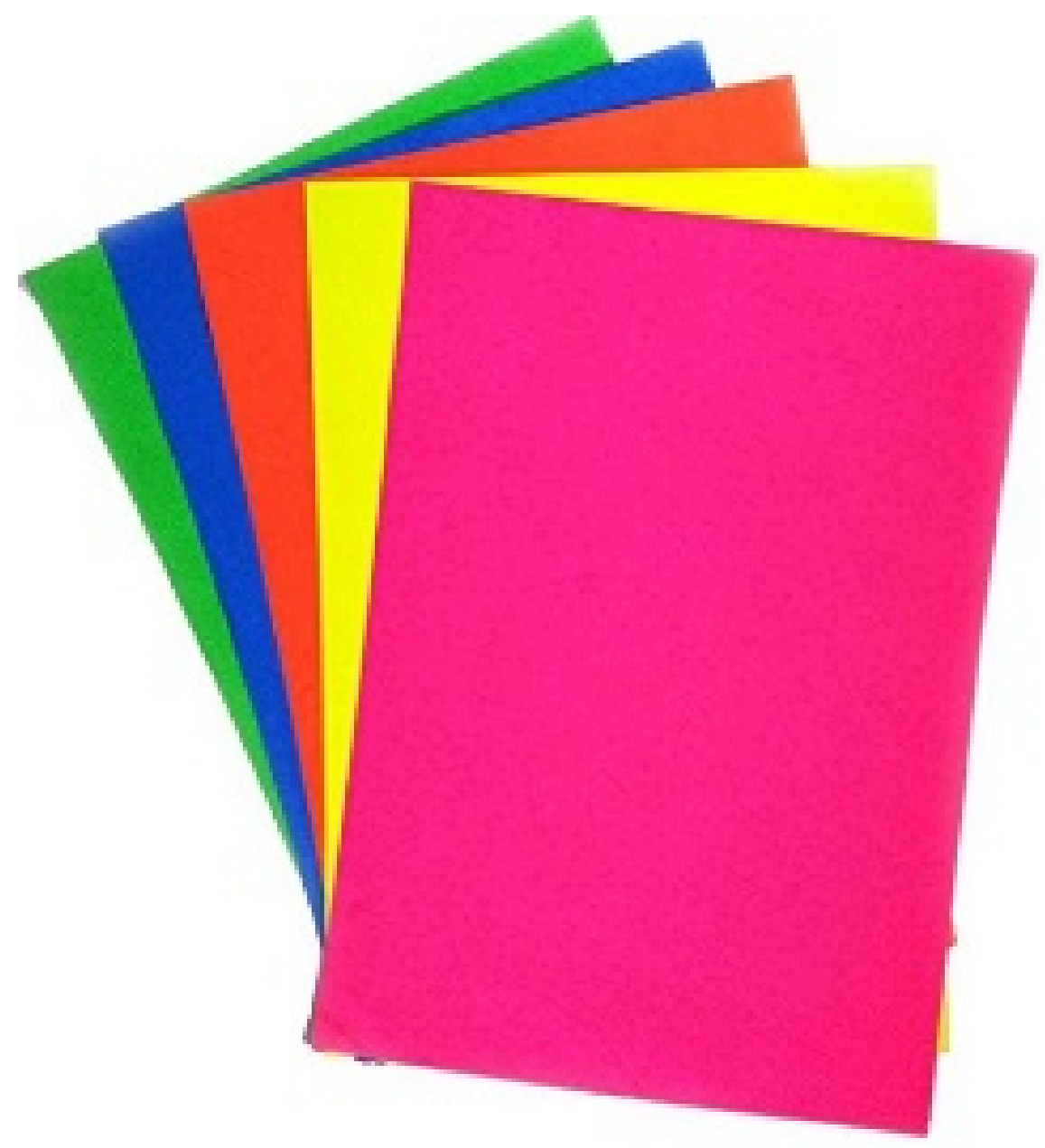




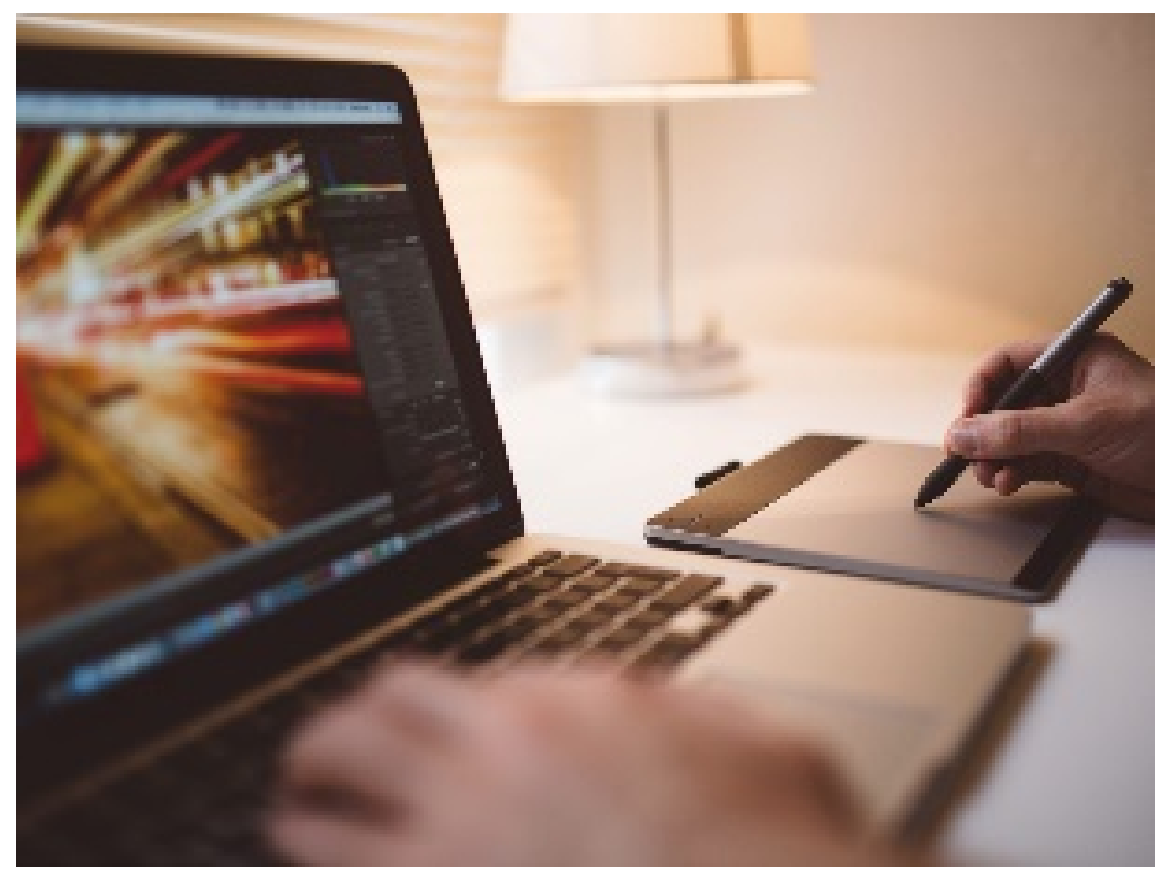

\section{Guidelines:}

1. Parents can manage their kids at home by providing the resources required.

2. Teachers can make teams of their students in group of 3-5 members.

3. Take four sets of simultaneous equations.

4. Solve that equations with the help of matrices.

5. Plot the coordinate points on graph paper, and join all the points to form a shape.

6. Cut the colored pages in the same shape and paste it on the chart.

7. With the resultant image, write its simultaneous equations, its matrix form, and its coordinate points.

8. Search for Graphic Designing app/software, and design the same image into that software.

9. Take pictures and screenshots of all of your STEM Activity and share it on the STEM Club page.

Note:

Activity can be performed in group or individually as well.

\section{Outcomes:}

- Aligned to lesson, Matrices.

- Develop critical thinking, communication, collaboration and creativity.

- Relate to life. (real world problems)

- Multi-disciplinary; measurement, technology, colors identification, engineering.

- Hands-on Activity.

- Several possible solutions.

Your findings:

What is the shape of your own designed image?

If you want to change the shape of the image then what is the most important point to change? 
Which app/software did you use for Graphic Designing?

How much time did you take in performing the above STEM activity? 